\title{
Optimal Cost Function Parameter Design in Predictive Torque Control (PTC) Using Artificial Neural Networks (ANN)
}

Novak, Mateja; Xie, Haotian; Dragicevic, Tomislav; Wang, Fengxiang; Rodriguez, Jose; Blaabjerg, Frede

Published in:

IEEE Transactions on Industrial Electronics

Link to article, DOI:

10.1109/TIE.2020.3009607

Publication date:

2021

Document Version

Peer reviewed version

Link back to DTU Orbit

Citation (APA):

Novak, M., Xie, H., Dragicevic, T., Wang, F., Rodriguez, J., \& Blaabjerg, F. (2021). Optimal Cost Function

Parameter Design in Predictive Torque Control (PTC) Using Artificial Neural Networks (ANN). IEEE

Transactions on Industrial Electronics, 68(8), 7309 - 7319. https://doi.org/10.1109/TIE.2020.3009607

\section{General rights}

Copyright and moral rights for the publications made accessible in the public portal are retained by the authors and/or other copyright owners and it is a condition of accessing publications that users recognise and abide by the legal requirements associated with these rights.

- Users may download and print one copy of any publication from the public portal for the purpose of private study or research.

- You may not further distribute the material or use it for any profit-making activity or commercial gain

- You may freely distribute the URL identifying the publication in the public portal 


\title{
Optimal Cost Function Parameter Design in Predictive Torque Control (PTC) Using Artificial Neural Networks (ANN)
}

\author{
M. Novak, Member, H. Xie, Student Member, T. Dragicevic, Senior Member, \\ F. Wang, Senior Member, J. Rodriguez, Fellow Member, and F. Blaabjerg, Fellow Member,
}

\begin{abstract}
The use of artificial neural networks (ANN) for the selection of weighting factors in cost function of the finite-set model predictive control (FS-MPC) algorithm can speed up selection without imposing additional computational burden to the algorithm and ensure that optimum weights are selected for the specific application. In this paper the ANN based design process of the weighting factors is used for predictive torque control (PTC) in a motor drive. In the design process the weighting factors in the cost function and the reference flux value are obtained using different fitness functions. The results show that different operating conditions of the drive will have new optimum parameters of the cost function, therefore sweeping parameters like load torque or reference speed can optimize the PTC for the whole operating range of the drive. A good match of the performance metrics predicted by the ANN and the simulation model is also observed. The experiments demonstrate that the selected cost function parameters can provide a fast drive start and good performance during different loading conditions and also in reversing of the drive.
\end{abstract}

Index Terms-artificial neural network (ANN), drives, model predictive torque control, voltage source converter (VSC), weighting factor design

\section{INTRODUCTION}

$\mathbf{M}$ ODEL predictive control algorithms have gained a lot of interest from power electronics control designers due to their simple design and the possibility to include multiple objectives in one cost function [1], [2]. Its ability to easily adapt to different power converter topologies, starting from

Manuscript received Oct. 8, 2019; revised Feb. 13, May 14 and June 24, 2020; accepted Jul. 3, 2020. This work is supported in part by National Natural Science Funds of China (Grant No. 51877207). (Corresponding author: Mateja Novak)

M. Novak and F. Blaabjerg are with the Department of Energy Technology, Aalborg University, Aalborg 9220, Denmark, (e-mail: nov@et.aau.dk, fbl@et.aau.dk).

$\mathrm{H}$. Xie is with the Institute for Electrical Drive Systems and Power Electronics, Technical University of Munich, Munich 80333, Germany (e-mail:haotian.xie@tum.de).

T. Dragicevic is with Center of Electric Power and Energy, Technical University of Denmark, 2800 Kgs. Lyngby, Denmark (e-mail: tomdr@elektro.dtu.dk).

F. Wang is with Quanzhou Institute of Equipment Manufacturing, Haixi Institutes, Chinese Academy of Sciences, Jinjiang 362200, China (email:fengxiang.wang@fjirsm.ac.cn).

J. Rodriguez is with Faculty of Engineering, Universidad Andres Bello, Santiago, 8370146, Chile (e-mail:jose.rodriguez@unab.cl). simple buck or boost converters [3], two level converters [4], [5], multilevel converters [6], [7] and modular multicell converters (MMC) [8] has helped this algorithm to spread to various fields of power electronics applications that have been dominated by traditional linear control algorithms. However, although the design might seem simple, the optimization of the cost function is more challenging than it looks. Each objective in the cost function is paired with a weighting factor that defines the contribution of this objective in the final control decision. If empirical methods like branch and bound search [9] are used, the optimization can be a very time consuming task and the complexity of this problem will increase exponentially with each added objective into the cost function. Therefore, a couple of different solutions have been proposed to solve this problem, from completely removing the weights in the cost function [4]-[7], [10]-[17], methods for online weighting factor adaptation [18]-[21] and also for offline adaptation based on ANN [22], [23] and even genetic algorithms [24], [25].

The most common approach to avoid using the weighting factors in the cost function for motor drives is to unify the dimensions of the control objectives as shown in [11], [12]. The methods do not impose any additional computational burden as they don't increase the complexity of cost function. Nevertheless, the methods are limited to use objectives that can be converted into a joint reference. An application of a weightless function with current control and neutral point (NP) voltage balancing was presented for three level converters in [6], [7]. In this application, first the voltage vector is selected to minimize the primary objective and then the redundant vectors are employed to control the secondary objectives. Controlling the secondary objectives only by redundant vectors can limit their control capability and is not applicable to all systems.

Recent PTC cost functions designs propose the splitting of the control problem into multiple cost functions, where each one of them has only one objective and the weighting factors are no longer needed [4], [5], [13]-[16]. For example in [4] the two cost functions, one for torque and one for flux, are evaluated in a sequence and in [5] in parallel. The authors of [13]-[16] also use a sequential structure for different converter topologies. It needs to be mentioned that multiple cost functions will also require the implementation of a ranking approach [15], [16]. In simulations and experimental results a better dynamic performance and stronger robust- 
ness to parameter mismatch is demonstrated for parallel cost functions compared to conventional cost functions with fixed weighting factors [5]. However, it remains unclear if more control objectives can effectively be included in the proposed cost function structures for PTC [4], [5].

The online based optimization methods proposed by the authors in [18], [19] are using fuzzy decision making and a ranking approach. Although the methods have demonstrated good performance, the authors have pointed out that it imposes an additional computational burden, which is expected to increase even more for multilevel converter applications or longer prediction horizons in the control. In [20] the online adaptation method adjusts the weights with the aim to prioritize the minimization of the objective with the largest error, but there is no analytical validation that the selected weights are optimally selected. A similar approach is also presented in [26] for a system with a parameter mismatch, where the autotuning algorithm will increase the weighting factor for the objective with an error larger than the set threshold. However, no guidelines were given how to set these thresholds. Another way to calculate the weighting factors online was shown in [27], where the weights are adjusted in every sampling period for each control criteria. Due to the weighting factor calculations the execution time of the algorithm is higher.

The ANN based methods in [22], [23] both use offline obtained training data from multiple simulations of the system model, though the optimization is performed differently. Authors in [22] use dynamic adaptation of the weighting factors. In each sampling step the trained ANN is fed with measured performance metrics to find the weighting factors that will keep the performance metrics in the defined limits for the system's safe operation. In [23] the weighting factors are static. Compared to [22] they are not chosen only to keep the system operating within the limits of safe operation, moreover they are optimized with certain analytical performance guarantee. The optimization is performed for the steady state, thus only static performance metrics are used in the optimization. For drives application, steady state performance metrics like THD of the controlled variable and switching frequency are not sufficient for optimization, dynamic parameters also need to be included. Multi-objective genetic algorithms (MOGA) are used to solve the problems that have more than one minimization goal, and therefore they can be utilized to optimize the weighting factors in the cost function with multiple conflicting objectives as it was demonstrated in [25].

An ANN based method for cost function parameter design with the goal to achieve optimal control of the motor will be presented in this paper. This paper will go one step further than [25] and also include the flux reference value in the optimization problem as well as evaluate the dependency of the cost function weighting factors on the different load values. It needs to be mentioned that none of the before mentioned weighting factor design methods has been used on such high complexity optimization problem. ANN based design method has not yet been applied for PTC and due to the fact that the cost function will have multiple conflicting objectives (3) it would be interesting to see if this method can also show a good performance as multi-objective optimization algorithm

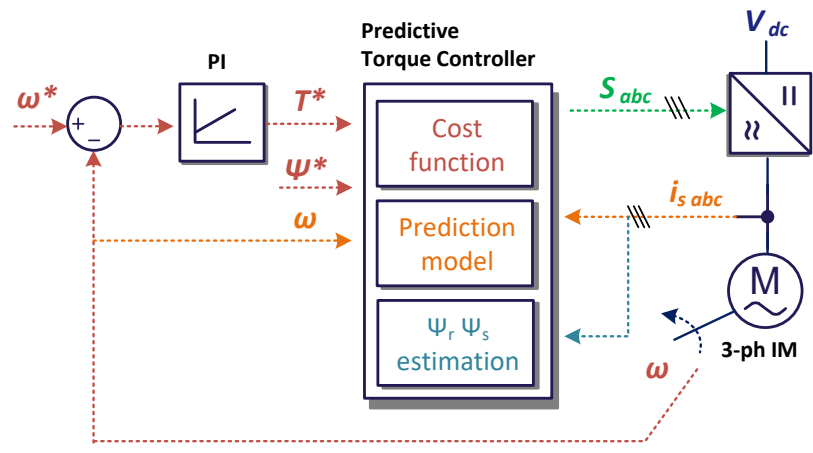

Fig. 1: Predictive torque control for a three phase voltage source converter feeding an 3-phase induction motor.

like in [25] and outperform the traditional heuristic methods. Dynamic performance factors will be used for optimization in order to have an analytical guarantee that the selected cost function parameters will lead to a successful drive start and operations under different loading conditions. We will show in the paper that the proposed approach:

1) Can be applied to cost functions with multiple conflicting objectives.

2) Can be applied for objectives, which can not be unified e.g. switching frequency and torque error.

3) Is not imposing any additional computational burden (tuning is performed offline).

4) It is analytically validated that the selected weights are the optimum combination with guaranteed dynamic performance.

5) The correlation of the predicted performance metrics from the trained ANN is very good both with the simulation and experimental results.

6) The design process is straightforward and has a large potential to be applied in the industry for tuning the PTC.

The paper is structured as follows. In Section II the system model and the control algorithm are introduced. How the ANN design method can easily be adapted to select the weighting factors of the PTC is shown in Section III. Moreover, recommendations are given which performance metrics should be used to train an accurate ANN that will represent the drive system and how a fitness function should be structured. The validation of the design can be found in Section IV. Conclusions and future work research aspects are given in Section V.

\section{SYSTEM MODEL}

In Fig. 1 a simplified scheme of the motor drive control that will be used for the weighting factor design is presented. For implementation of the PTC, measurements of the inverter currents $\mathbf{i}_{\mathbf{s}}^{k}$ and motor speed $\omega$ are needed. The torque reference is obtained from the PI speed controller. To control the motor torque, predictions of the future stator current $\left(\mathbf{i}_{\mathbf{s}}^{k+1}\right)$, torque $\left(\hat{T}^{k+1}\right)$ and stator flux $\left(\hat{\Psi}_{\mathbf{s}}^{k+1}\right)$ values have to be calculated for all possible switching states of the two level voltage source converter using the discretized system equations: 


$$
\begin{aligned}
\mathbf{i}_{\mathbf{s}}^{k+1} & =k_{1} \mathbf{i}_{\mathbf{s}}^{k}+\frac{T_{s}}{L_{\sigma}} \mathbf{v}_{\mathbf{s}}^{k}+k_{2} \hat{\Psi}_{\mathbf{r}}^{k} \\
\hat{T}^{k+1} & =\frac{3}{2} p \Im\left\{\hat{\Psi}_{s}^{k+1 *} \cdot \mathbf{i}_{\mathbf{s}}^{k+1}\right\} \\
\hat{\Psi}_{\mathbf{s}}^{k+1} & =\hat{\Psi}_{\mathbf{s}}^{k}+T_{s} \mathbf{v}_{\mathbf{s}}^{k}-T_{s} R_{s} \mathbf{i}_{\mathbf{s}}^{k}
\end{aligned}
$$

where:

$$
\begin{aligned}
k_{1} & =\left(1-\left(R_{\sigma} T_{s} / L_{\sigma}\right)\right) \\
k_{2} & =\left(L_{m} / L_{r}\right) T_{s} / L_{\sigma}\left(\left(R_{r} / L_{r}\right)-j \omega^{k}\right) \\
R_{\sigma} & =R_{s}+\left(L_{m} R_{r} / L_{r}\right)^{2} R_{r}
\end{aligned}
$$

and $R_{s}, L_{s}, R_{r}, L_{r}, L_{m}, p$ are the parameters of the induction machine. Stator and rotor flux estimations $\left(\hat{\Psi}_{\mathbf{s}}^{k}, \hat{\Psi}_{\mathbf{r}}^{k}\right)$ are calculated as presented in [19]. A forward-Euler discretization is used with a sample period $T_{s}$ to obtain the discrete system equations. The effects of the computational delay have been compensated as shown in [19]. In Table I the system parameters which are used to build a simulation model are shown and they correspond to the parameters in the experimental setup too. The sampling frequency was selected by finding a trade-off between the control performance and the computing power of the DSP platform. To execute the PTC algorithm, the controller in the available experimental platform, requires 25 $\mu \mathrm{s}$. Considering the calculation time and performance, the PTC algorithm is suitable for operation with a sampling frequency range between $10 \mathrm{kHz}$ and $30 \mathrm{kHz}$ to avoid the overruns. For the $T_{s}$ in Table I we have observed in the experiments that the selected frequency can provide a good dynamic controller response and strong steady state operation.

\section{A. Cost function}

Typically, the cost function used in PTC has two objectives: torque and flux control. However, due to the lack of modulator in the control scheme (Fig. 1) the switching frequency is variable. In order to limit the average switching frequency per device i.e. reduce the commutation number between two consecutive sampling periods, an additional objective is added to the cost function. Thus, the cost function will have the following structure:

$g=\left|T^{*}-\hat{T}^{k+2}\right|+\lambda_{\Psi}\|\| \Psi_{\mathbf{s}}^{*}\|-\| \hat{\Psi}_{\mathbf{s}}^{k+2} \| \mid+\lambda_{s w^{\prime}} \cdot n_{s w}+h_{l i m}$,

where:

$$
\begin{aligned}
h_{\text {lim }} & =\left\{\begin{array}{l}
0, \text { if }\left|\bar{i}_{s}\right| \leq i_{\max } \\
\infty, \text { if }\left|\bar{i}_{s}\right|>i_{\max }
\end{array}\right. \\
n_{s w} & =\sum_{x=a, b, c}\left|S_{x}(k)-S_{x}(k-1)\right| \\
\lambda_{s w^{\prime}} & =\frac{T_{n o m}}{\Psi_{n o m}} \lambda_{s w}
\end{aligned}
$$

$h_{\text {lim }}$ is limiting the current to maximal allowed stator current of the machine $i_{\max }$ and $n$ defines the number of switches that changed the state. Therefore, $S_{x}(k)$ is the switching state that will be applied to the device and $S_{x}(k-1)$ is the applied switching state in the previous sampling period. $\lambda_{\Psi}, \lambda_{s w}$ are the weighting factors; $T^{*}, \Psi_{s}^{*}$ are the torque and flux reference values and $T_{n o m}, \Psi_{\text {s nom }}$ are the nominal values.
TABLE I: System parameters.

\begin{tabular}{ccc}
\hline Description & Parameter & Value \\
\hline Stator and rotor resistance & $R_{s}, R_{r}$ & $2.68 \Omega, 2.13 \Omega$ \\
Stator and rotor inductance & $L_{s}, L_{r}$ & $283.4 \mathrm{mH}, 283.4 \mathrm{mH}$ \\
Mutual inductance, pole pairs & $L_{m}, p$ & $275.1 \mathrm{mH}, 1$ \\
Nominal torque and power & $T_{n o m}, P_{n o m}$ & $7.5 \mathrm{Nm}$, \\
Nominal flux and speed & $\psi_{s}$ nom,$n_{n o m}$ & $0.99 \mathrm{~Wb}, 290 \mathrm{rad} / \mathrm{s}$ \\
Supplied DC-link voltage & $V_{d c}$ & $582 \mathrm{~V}$ \\
Speed PI controller gains & $K_{p}, K_{i}$ & 10,10 \\
Controller sampling frequency & $T_{s}$ & $62.5 \mu \mathrm{s}$ \\
\hline
\end{tabular}

\section{B. Problem complexity}

For the defined cost function (7) three parameters need to be designed: $\lambda_{\Psi}, \lambda_{s w}$ and $\Psi_{s}^{*}$. If 10 different values are assigned to each of these parameters, the complexity of the design problem is $10^{3}=1000$. It is evident that using the traditional branch and bound method introduced in [9] would be time consuming with this problem complexity as the cost function has two equally important terms $\left(T^{*}\right.$ and $\left.\Psi_{s}^{*}\right)$ and one secondary term $\left(n_{s w}\right)$. It is also possible to end into a local minimum, as the tuning will be done hierarchically. Moreover, the method would need to be performed several times in order to obtain the weighting factors for different $\Psi_{s}^{*}$ values.

\section{WEIGHTING FACTOR DESIGN USING ANN}

In the weighting factor design process the ANN network will serve as a surrogate of the system model presented in Fig. 1. The design approach is illustrated in Fig. 2, where it can be seen that the ANN is trained using the performance metrics obtained from multiple simulations for various weighting factor combinations. After the training, a fitness function $\left(f_{A N N}\right)$ can be constructed using the performance metrics to find the optimum combination of parameters. A feed-forward ANN structure will be used with a back-propagation training algorithm as suggested in [23]. The structure of the ANN is the following: 3 neurons in the input layer, 12 neurons in the first hidden layer, 5 neurons in the second hidden layer and 5 neurons in the output layer. The design steps can be followed in the flow-chart shown in Fig. 3.

The sweeping range for the parameters in the cost function (7) was selected as follows: $\lambda_{\Psi}=[1.6,2.8 \ldots 10], \lambda_{s w}=$ $[0,0.1, \ldots 0.7], \Psi_{s}^{*}=[0.65,0.7, \ldots 1]$. It can be noticed that the range was adjusted to sweep only the combinations that can lead to a successful start and steady state operation of the drive e.g sweeping the $\Psi_{s}^{*}$ for values below 0.65 (reference flux below $65 \%$ of the $\Psi_{s \text { nom }}$ ) or $\lambda_{s w}$ for values above 0.7 would not result in a stable operating points. In total 512 different parameter combinations were sweeped in 12 min using Parallel Computing Toolbox from MATLAB with 24 processor cores.

The user can of course beforehand fix the flux reference and sweep only the weighting factor values if the $\Psi_{s}^{*}$ needs to be kept constant. However, in dynamic conditions such as acceleration and deceleration of the drive, the flux reference can be selected to optimize the torque for its maximum value or minimum value. For this selection criteria $T_{\text {mean }}$ performance metrics can also be used in the fitness function. 
I. Training data generation

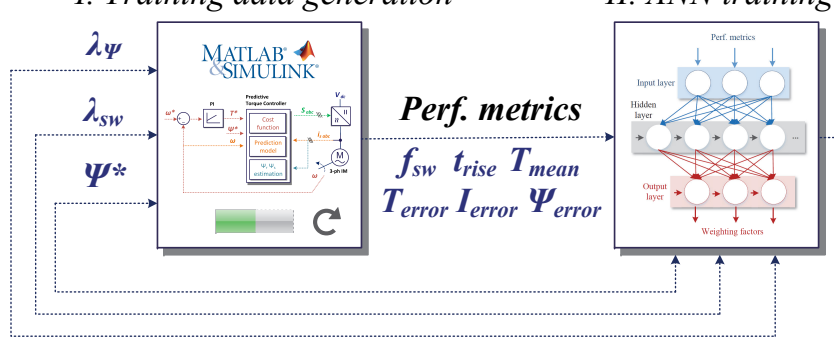

II. ANN training

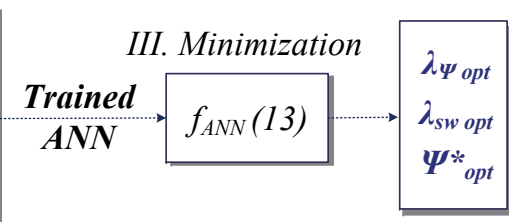

Fig. 2: Block scheme of the cost function parameter design for PTC using the ANN approach.

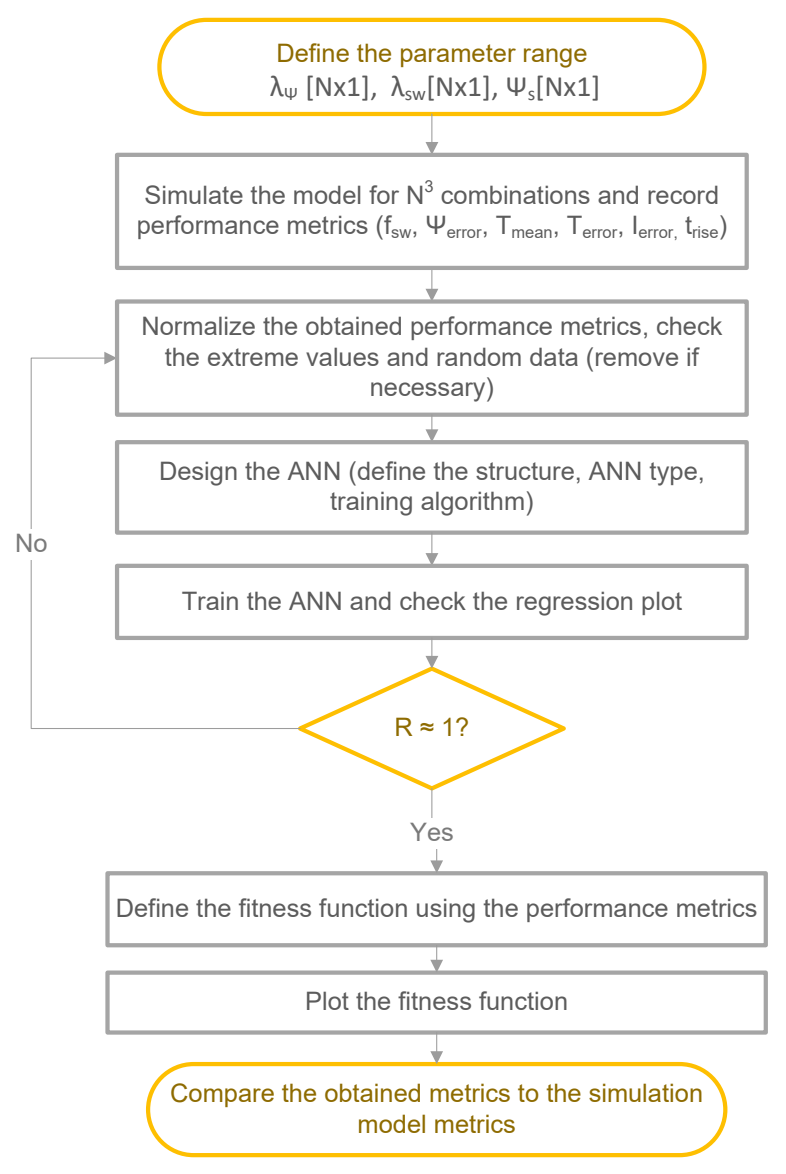

Fig. 3: Flowchart for design of the PTC cost function parameters using the ANN approach.

Moreover in the field weakening operation of the drive the flux reference is reduced, thus it makes sense to also include the flux reference in the cost function optimization process.

According to the cost function in (7), which has three objectives, the following performance metrics will be used to train the ANN: mean torque $\left(T_{\text {mean }}\right)$; torque, stator and current rms errors $\left(T_{\text {error }}, \psi_{\text {serror }}, I_{\text {s error }}\right)$, time needed to reach $98 \%$ of the $\omega_{\text {ref }}$ at drive start $\left(t_{\text {rise }}\right)$ and the average switching frequency per device $\left(f_{\text {swavg }}\right)$.

\section{A. Design for drive start}

To find the cost function parameters for the fastest drive start, using $t_{\text {rise }}$ metrics in the fitness function is sufficient:

$$
f_{A N N}=t_{\text {rise }}^{2}
$$

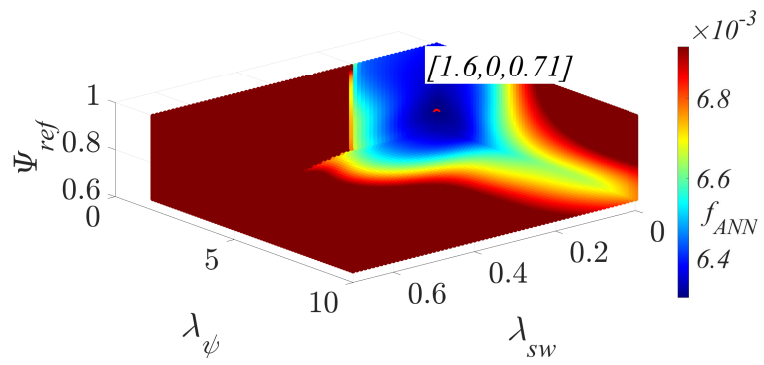

Fig. 4: Plot of the fitness function in (11). Obtained optimum parameter values: $\lambda_{\Psi}=1.6, \lambda_{s w}=0$ and $\Psi_{s}^{*}=0.81$.

The plot of the fitness function in Fig. 4 shows the area of optimum cost function parameters. For the selected optimum parameters $\left[\lambda_{\Psi}=1.6, \lambda_{s w}=0\right.$ and $\left.\Psi_{s}^{*}=0.81\right]$ the ANN predicted that the drive can reach $98 \%$ of the reference speed in $0.158 \mathrm{~s}$ with a $T_{\text {load }}=1 \mathrm{Nm}$, while the simulation for the same parameters showed that $0.159 \mathrm{~s}$ are necessary. However, in the current waveform of the simulation model it can be observed that the distortion is high when the reference speed is reached, see Fig 5. It can also be noticed that the stator current limiter in the cost function $h_{\text {lim }}$ will limit the amplitude of the inrush current. Thus, for a better performance in the loading operation different fitness function needs to be used for selecting the parameters in loading operation.

\section{B. Design for loading operation}

Following fitness function for different loading conditions is recommended:

$$
f_{A N N}=\psi_{\text {serror }}^{2}+I_{\text {serror }}^{2}+T_{\text {serror }}^{2}+\left(f_{1}-f_{\text {sw avg }}\right)^{2}
$$

where $f_{1}$ is the $f_{\text {sw avg }}$ for which we would like to obtain the optimum parameter values and it is chosen arbitrary. In Fig. 6 and Fig. 7 the surfaces containing the optimum parameter combinations show similar trends in both fitness plots. The size of the surface containing the combinations of optimum parameters is being reduced for $T_{\text {load }}=5 \mathrm{Nm}$ and therefore decreasing the optimum range of the weighting factors. For higher loads it is expected that the surface will be even smaller with high values of $\lambda_{\Psi}$ and low values of $\lambda_{s w}$ defining the optimum parameter region. While on one hand the fidelity of the cost function parameters was reduced, the optimum cost function parameters obtained for low load needed just a slight change for higher load conditions. However, if the reference speed is reduced, as shown in Fig. 8, the surface 

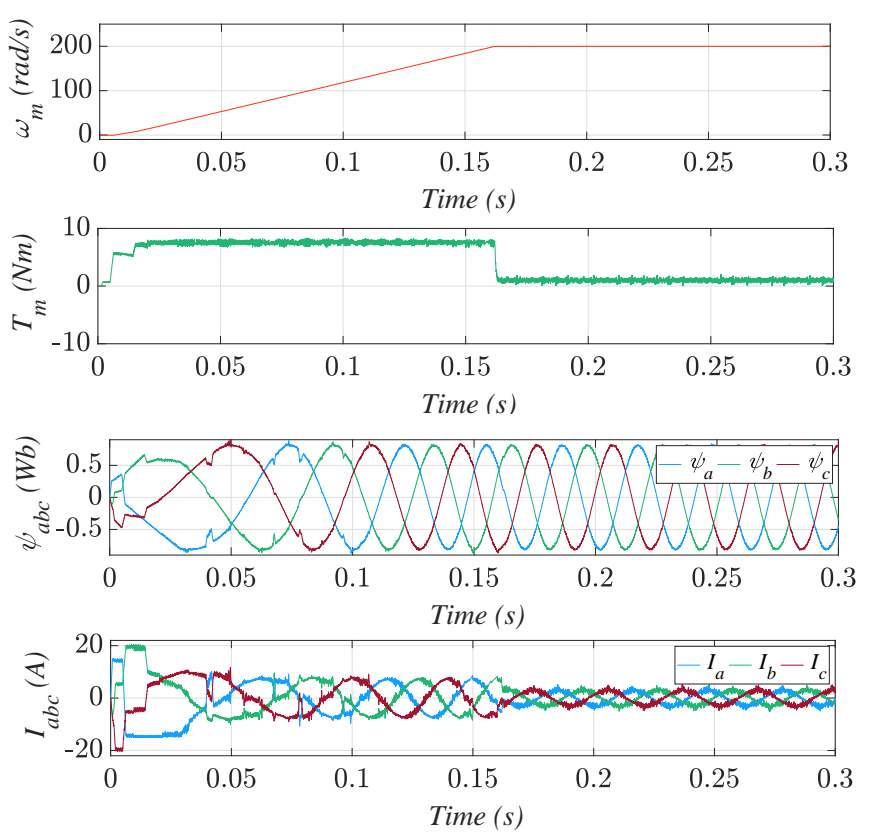

Fig. 5: Drive speed, torque, stator flux and current waveforms from simulation model for (11). Parameter values: $\lambda_{\Psi}=$ $1.6, \lambda_{s w}=0$ and $\Psi_{s}^{*}=0.81$.

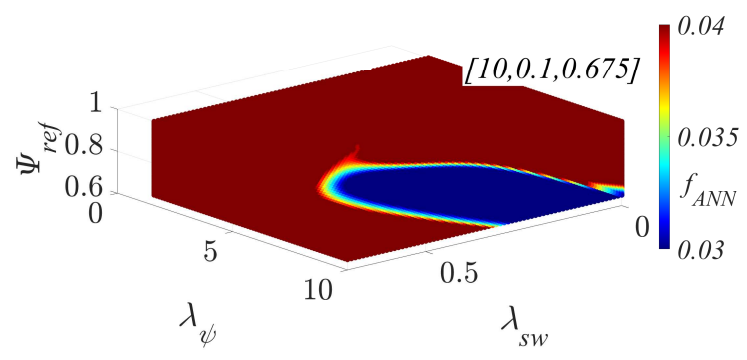

Fig. 6: Plot of the fitness function in (12) for $f_{1}=2.5 \mathrm{kHz}$, $\omega_{\text {ref }}=200 \mathrm{rad} / \mathrm{s}, T_{\text {load }}=2 \mathrm{Nm}$. Obtained optimum parameter values: $\lambda_{\Psi}=10, \lambda_{s w}=0.1$ and $\Psi_{s}^{*}=0.67$.

containing the combinations of optimum parameters becomes very wide while the boundary between the low $f_{A N N}$ and high $f_{A N N}$ values becomes very narrow. The fidelity of $\Psi_{s}^{*}$ and $\lambda_{\Psi}$ combinations is increased compared to other $f_{A N N}$ plots, offering the opportunity to obtain a good performance for different $\Psi_{s}^{*}$. In Fig. 9 it can be observed that for the nominal conditions the number of parameter combinations that can provide the same performance as previous designs is much lower. The use of switching frequency minimization is not necessary to achieve the design reference $f_{1}$. Moreover, the presented $f_{A N N}$ plots show that the parameter combinations for the nominal conditions would not provide the same performance for other operating points.

The proposed method can also be applied to design the weighting factors of PTC with multilevel inverters. For example in a neutral point clamped topology a new performance metrics $\Delta v_{d c}$, representing the NP voltage balancing, needs to be calculated for all sweept cost function parameters and afterwards included in the ANN training and in $f_{A N N}$.

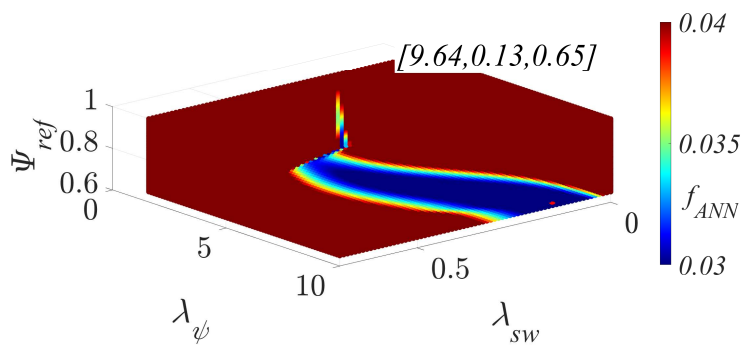

Fig. 7: Plot of the fitness function in (12) for $f_{1}=2.5 \mathrm{kHz}$, $\omega_{\text {ref }}=200 \mathrm{rad} / \mathrm{s}, T_{\text {load }}=5 \mathrm{Nm}$. Obtained optimum parameter values: $\lambda_{\Psi}=9.64, \lambda_{s w}=0.13$ and $\Psi_{s}^{*}=0.65$.

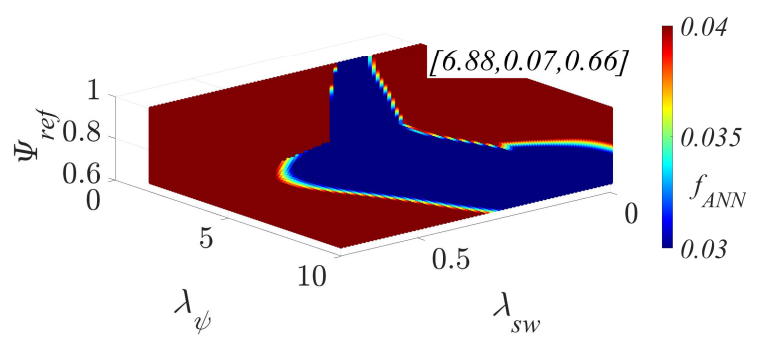

Fig. 8: Plot of the fitness function (12) for $f_{1}=2.5 \mathrm{kHz}$, $\omega_{\text {ref }}=150 \mathrm{rad} / \mathrm{s}, T_{\text {load }}=5 \mathrm{Nm}$. Obtained optimum parameter values: $\lambda_{\Psi}=6.88, \lambda_{s w}=0.07$ and $\Psi^{*}=0.66$.

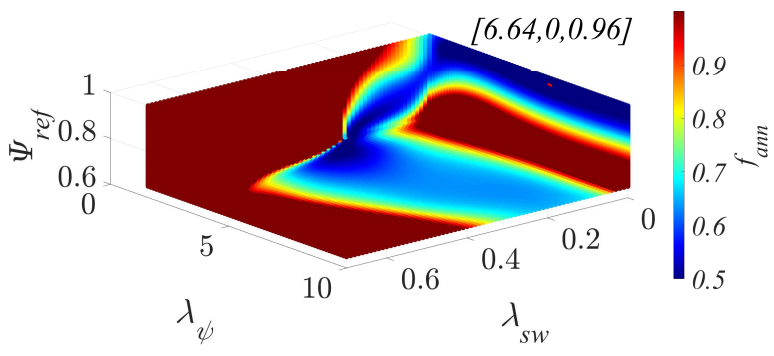

Fig. 9: Plot of the fitness function (12) for $f_{1}=2.5 \mathrm{kHz}, \omega_{\text {ref }}$ $=290 \mathrm{rad} / \mathrm{s}, T_{\text {load }}=7.5 \mathrm{Nm}$. Obtained optimum parameter values: $\lambda_{\Psi}=6.64, \lambda_{s w}=0$ and $\Psi^{*}=0.96$.

\section{DEsign VALIDATION}

The predicted performance metrics for the optimum cost function parameter values are validated using the simulation model. Afterwards the obtained optimum cost function parameters are experimentally validated. Due to the space limitations, only simulation waveforms for the $T_{\text {load }}=5 \mathrm{Nm}$ and nominal torque are shown in Fig. 10 - 13. The test profile is the following: start of the drive at $2 s$, reversing of the drive at $5 s$ and loading at $8 s$. It is observed that the parameters can provide a good steady state performance, fast start of the drive and successful speed reversing. The $f_{\text {sw avg }}$ is matching the set point in the cost function. Fig. 11 and Fig. 13 show the current and stator flux waveforms in the steady state. Table II shows a comparison of obtained metrics from simulations and predicted values by the ANN. A high accuracy of the metrics can be observed. 

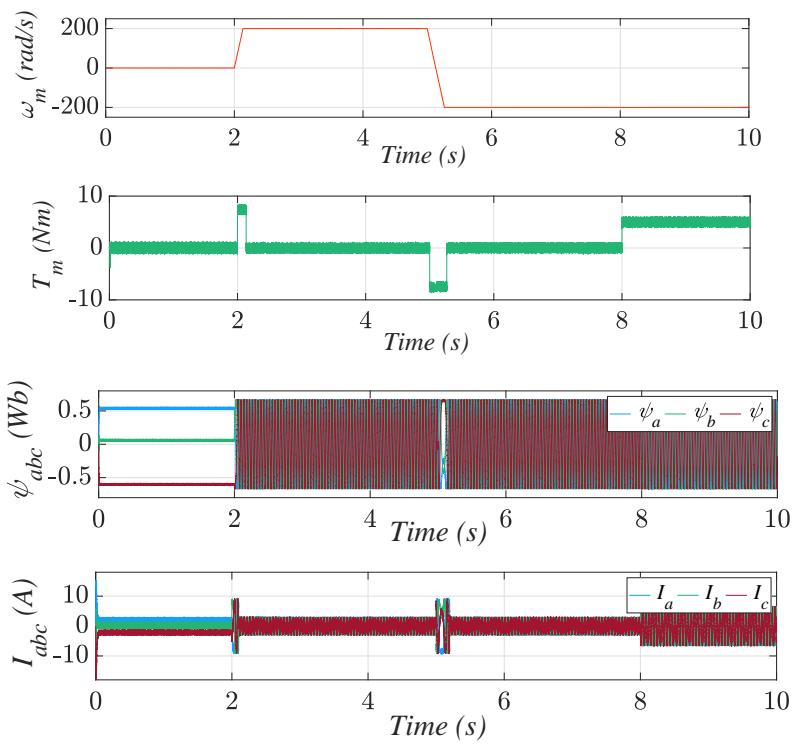

Fig. 10: Drive speed, torque, stator flux and current waveforms in simulation model for (12) and $T_{\text {load }}=5 \mathrm{Nm}$, $f_{1}=2.5 \mathrm{kHz}, \lambda_{\Psi}=9.64, \lambda_{s w}=0.13$ and $\Psi_{s}^{*}=0.65$.
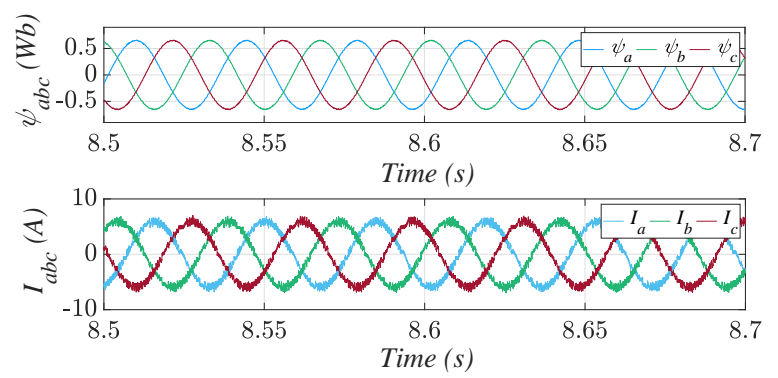

Fig. 11: Stator flux and current waveforms in steady state for (12) and $T_{\text {load }}=5 \mathrm{Nm}, f_{1}=2.5 \mathrm{kHz}, \omega_{\text {ref }}=-200 \mathrm{Rad} / \mathrm{s}$, $\left(T H D_{i_{s}}=7.8 \%\right)$.

TABLE II: Comparison of performance metrics from ANN, simulation model and experiments.

\begin{tabular}{ccccc}
\hline Metrics & $\boldsymbol{T}_{\text {load }}$ & ANN & Simulation & Experiments \\
\hline$f_{\text {swavg }}$ & $5 \mathrm{Nm}$ & $2.56 \mathrm{kHz}$ & $2.54 \mathrm{kHz}$ & $2.32 \mathrm{kHz}$ \\
$\psi_{\text {s error }}$ & $5 \mathrm{Nm}$ & $<0.004 \mathrm{~Wb}$ & $<0.004 \mathrm{~Wb}$ & $<0.06 \mathrm{~Wb}$ \\
$T_{\text {error }}$ & $5 \mathrm{Nm}$ & $0.35 \mathrm{Nm}$ & $0.32 \mathrm{Nm}$ & $0.5 \mathrm{Nm}$ \\
$I_{\text {s error }}$ & $5 \mathrm{Nm}$ & $0.39 \mathrm{~A}$ & $0.4 \mathrm{~A}$ & $0.37 \mathrm{~A}$ \\
\hline$f_{\text {swavg }}$ & $2 \mathrm{Nm}$ & $2.45 \mathrm{kHz}$ & $2.51 \mathrm{kHz}$ & $2.3 \mathrm{kHz}$ \\
$\psi_{\text {serror }}$ & $2 \mathrm{Nm}$ & $<0.005 \mathrm{~Wb}$ & $<0.005 \mathrm{~Wb}$ & $<0.06 \mathrm{~Wb}$ \\
$T_{\text {error }}$ & $2 \mathrm{Nm}$ & $0.37 \mathrm{Nm}$ & $0.33 \mathrm{Nm}$ & $0.46 \mathrm{Nm}$ \\
$I_{\text {serror }}$ & $2 \mathrm{Nm}$ & $0.33 \mathrm{~A}$ & $0.36 \mathrm{~A}$ & $0.37 \mathrm{~A}$ \\
\hline
\end{tabular}

\section{A. Comparison with the conventional design method}

Using the conventional branch and bound design method presented in [9] optimum parameters of the cost function (7) will be defined. The design process will be simplified by fixing the $\Psi^{*}$ value to 0.67 , which is the optimum value obtained for the light load design in Section III-B. In the first design step $\lambda_{s w}$ will be fixed to 0 and the $\lambda_{\Psi}$ will be set to one of the
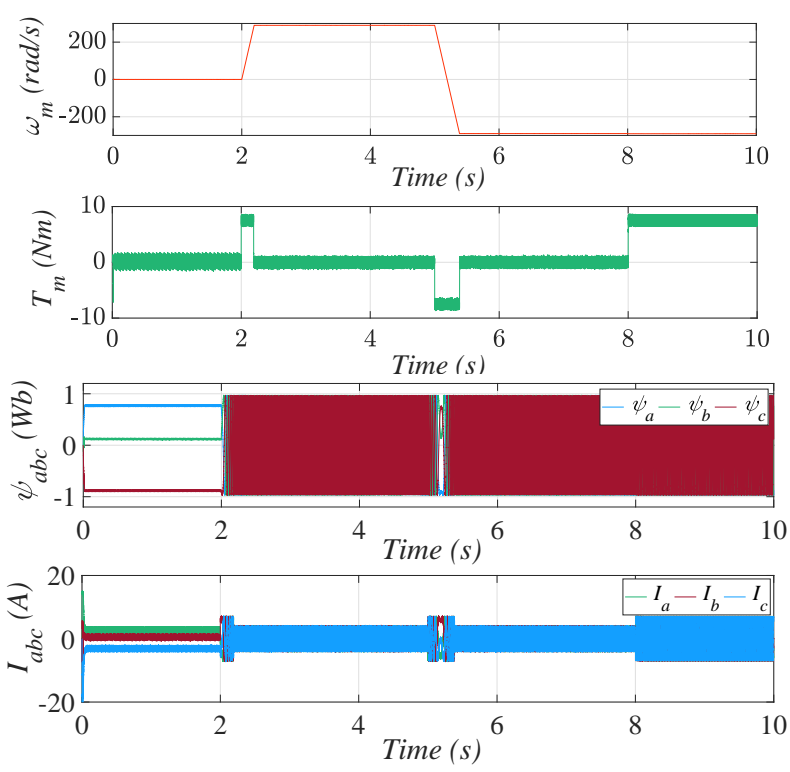

Fig. 12: Drive speed, torque, stator flux and current waveforms in simulation model for (12) and $T_{\text {load }}=7.5 \mathrm{Nm}$, $f_{1}=2.5 \mathrm{kHz}, \lambda_{\Psi}=6.64, \lambda_{s w}=0$ and $\Psi^{*}=0.96$.

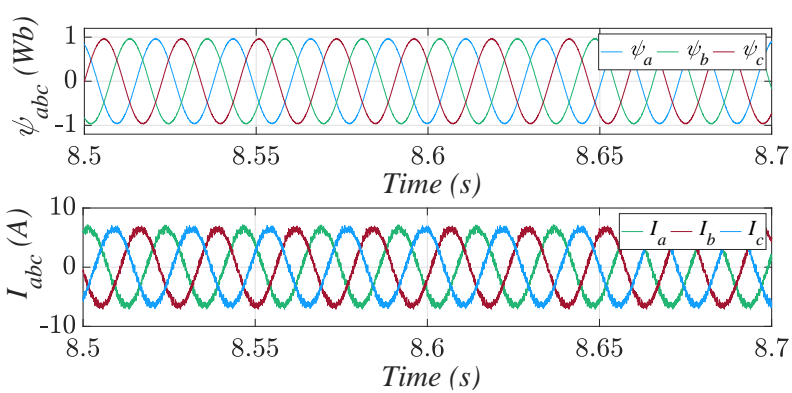

Fig. 13: Stator flux and current waveforms in steady state for (12) and $T_{\text {load }}=5 \mathrm{Nm}, f_{1}=2.5 \mathrm{kHz}, \omega_{\text {ref }}=-200 \mathrm{Rad} / \mathrm{s}$, $\left(T H D_{i_{s}}=6.6 \%\right)$.

following values: $0.01,0.1,1,10$ and 100 as suggested in [9] to find the best interval for the next step in the branch and bound algorithm. The same performance metrics as for ANN design method will also be used for control performance assessment.

For $\lambda_{\Psi}=1$, the metrics showed $T_{\text {error }}=0.19 \mathrm{Nm}, I_{\text {s error }}$ $=0.52 \mathrm{~A}, f_{\text {swavg }}=3.9 \mathrm{kHz}, \psi_{\text {serror }}=0.04 \mathrm{~Wb}, t_{\text {rise }}=$ $0.158 \mathrm{~s}$, but at the same time the current analysis showed large distortion (THD $=11 \%$ ) and high spikes during the speed reversing of the drive. The intervals with $\lambda_{\Psi} \leq 1$ were eliminated after this step. In the second step the simulations were repeated for $\lambda_{\Psi}=10$ and following metrics were obtained: $T_{\text {error }}=0.33 \mathrm{Nm}, I_{\text {serror }}=0.36 \mathrm{~A}, f_{\text {swavg }}=3$ $\mathrm{kHz}, \psi_{\text {serror }}=0.005 \mathrm{~Wb}, t_{\text {rise }}=0.168 \mathrm{~s}$. These metrics showed an improved performance compared to the previous intervals. Simulations were also performed for $\lambda_{\Psi}=100$ but the performance was not improved. Therefore, the interval $5 \leq \lambda_{\Psi} \leq 15$ was selected for the second iteration and a better trade off was obtained for the $\lambda_{\Psi}=15$. The weighting factors $\lambda_{\Psi}=10$ and $\lambda_{\Psi}=15$ have shown just a small difference in the performance metrics and either of them could be chosen for the final selection at this optimization step. In our case we 
have selected $\lambda_{\Psi}=15$ for the next step.

The next task is to select the weighting factor for the secondary objective $\lambda_{s w}$ to match the target of $f_{1}=2.5$ $\mathrm{kHz}$. The value of the $\lambda_{s w}$ will be increased gradually from 0 to reduce the switching frequency. At the same time the torque and flux performance metrics will also be monitored as it is expected that they will degrade due to the conflicting objectives. First simulation was performed for $\lambda_{s w}=0.0001$ for which $f_{\text {swavg }}$ was reduced to $2.3 \mathrm{kHz}$. We can conclude that for $\lambda_{\Psi}=15$ it is not possible to obtain switching frequency of $2.5 \mathrm{kHz}$, as even the smallest value of the weighting factor decreased the switching frequency too much. Therefore, $\lambda_{\Psi}$ was changed to value 10 and the procedure of tuning $\lambda_{s w}$ was repeated. For $\lambda_{s w}=0.05$ the switching frequency of $2.51 \mathrm{kHz}$ was obtained and the performance metrics now match the ANN based tuning results. Thus, this proves that if a cost function that has two equally important objectives and a secondary objective it will need more optimization iterations, which are necessary to perform for ANN based method. Moreover, as we don't explore the full range of the weighting factor combinations, it is not certain that the selected combination is the optimum. This is often the case when conflicting objectives are used in the cost function.

\section{B. Comparison with sequential PTC}

One of the most trending weighting factor less solutions is to split the PTC cost function into two cascading functions. The problem with this structure is that if in first cost function which evaluates the flux control only two candidate vectors are passed to the second cost function with torque control, the applied candidate vector can potentially lead to an unstable system response as demonstrated in [17]. It is also problematic if control variables have equal importance. The first problem was solved by increasing the number of candidate vectors that are selected in the first cost function from 2 to 3 vectors. On the other hand, the conventional PTC algorithm used in this paper evaluates all candidate vectors only once and it has the flexibility to also minimize the switching frequency if required without the risk to run out of candidate vectors. The difference is also in the optimization flexibility, the conventional PTC can find a good trade off in both torque and flux reference tracking. If sequential structure is used, one must prioritize either the torque or the flux reference tracking performance.

If performance of the generalized sequential MPC (GSMPC) proposed in [17] is compared to the performance obtained using the conventional PTC algorithm designed in Section III-B we can see that both methods can provide a stable response during start up, speed reversing and steady state operation under nominal conditions. Both methods also outperform the sequential MPC when flux control is used in the first cost function. Moreover, the field weakening method proposed in [17] could potentially also be applied to a conventional PTC as it is only effecting the calculation of torque and stator flux reference and not the prediction model or the cost function. In conclusion, the biggest advantage of GSMPC is that even without the weighting factors relatively good performance can be achieved if either flux or torque are given the priority to be used in the first cost function. What could potentially be a disadvantage compared to conventional PTC is the lack of switching frequency control, potential problems in the implementation of cost functions with more than 2 control objectives (there should be a guarantee that each cost function in the cascade has sufficient number of vector candidates) and how to treat the control objectives that have an equal importance. It is also not shown how limitations of e.g. stator current, that can easily be implemented in the conventional PTC, will effect the cascaded structure.

\section{Experimental validation}

Two design cases were also validated on an experimental set-up shown in Fig. 14, which includes two induction motors with the parameters provided in the Table I, a Servostar620 inverter used to control the drive motor and a Danfoss inverter used to drive the load machine and 1024-point incremental encoder for obtaining the rotor position. The control algorithm is implemented on a $1.4 \mathrm{GHz}$ real time computer system. The controller sampling frequency is set to $16 \mathrm{kHz}$ and the test profile is equivalent to the one used in the simulations. In Fig. 15 the experiments were performed for $T_{\text {load }}=2$ $\mathrm{Nm}$ and in Fig. 16 for $T_{\text {load }}=5 \mathrm{Nm}$. It can be observed that both cost function parameter values obtained in Section III-B were able to provide a fast start of the drive, a stable speed reversing and a steady state performance under loading conditions. In Table II it can be observed that the obtained performance metrics in the steady state are similar for both design cases, which confirms that the chosen cost function parameters can give a constant performance for both load values. The average switching frequency obtained from the experiments was $2.3 \mathrm{kHz}$, which is only $8 \%$ lower than the average switching frequency set in the design. Because the simulation model was optimized for fast execution, a detailed induction machine model was not used. Therefore we can notice the difference compared to the simulations. For better accuracy of the performance metrics with the ANN predictions, the training can be performed using a detailed model or the experimental data. It needs to be mentioned that a detailed model will increase the simulation time in the first stage of the training data collection. The experimental data extraction could be done either in an automated fashion or manually. There are several risks associated with automated data extraction. Unfeasible combination of weighting factors may cause a system damage. Thus, a human operator is required to oversee this process.

\section{Robustness validation}

The accuracy of the motor model parameters is important for PTC as predictions of the torque and stator flux are calculated using the discrete system model. There are three alternatives, which can help to improve the robustness of the weighting factors design:

\section{1) Experimental extraction of the training data}

It would ensure a higher accuracy of the performance metrics but also require more time and human supervision, as it is potentially possible that the induction 
motor or the converter gets damaged if an unfeasible combination of weighting factors is tried.

2) Include the parameter uncertainty in the simulations This approach will require to run additional simulations with overestimated and underestimated parameter values of the drive making it more time consuming. However, compared to the first alternative it can automatized, parallelized and performed without human supervision. In our future work, we plan to investigate the possibilities of the robustness inclusion in the training data.

3) Perform robustness validation after the simulation This approach does not require any changes of the proposed weighting factor design. After the optimum weighting factors are obtained using the fitness function, a robustness validation of the designed cost function can be performed using a statistical model checking (SMC) approach that was proposed in [28]. The approach is not topology or application dependent and can thus be applied also to PTC.

Experimental evaluation for parameter mismatch of stator resistance $\left(R_{s}\right)$ and mutual inductance $\left(L_{m}\right)$ can be seen in Fig. 17 and Fig. 18, where values of stator resistance were varied from $100 \%-150 \% R_{s \text { nom }}$ and mutual inductance from $100 \%-200 \% L_{m \text { nom }}$ respectively. It can be observed that the system is more robust against mismatch of $L_{m}$ while high mismatch of $R_{s}$ can lead to system instability. Using the simulation model, we have repeated the robustness test also for nominal torque and speed. A similar performance was obtained, a high resistance to variation of $L_{m}$ and a loss of stability at $140 \% R_{\text {s nom }}$.

\section{E. Computation burden}

The computation burden of the PTC algorithm used in this paper is equivalent to the conventional PTC algorithm. In each sampling period the algorithm needs to evaluate 8 vector candidates in the cost function (7). The turn-around time of the PTC algorithm used in the manuscript on the available experimental platform is about $25 \mu \mathrm{s}$. With applied $16 \mathrm{kHz}$ sampling frequency, the sampling interval is sufficient to execute the PTC algorithm without overruns. Due to the fact that the weighting factor optimization is performed offline, there is no additional computation burden during execution of the algorithm. The same also applies for the algorithm proposed in [25]. For method proposed in [22] the selection of the weighting is performed online using the ANN whenever the reference changes and this adds an additional computation burden. If the use of weighting factors is avoided, the computational burden will increase as more vector candidates need to evaluated. For example, the sequential PTC [4] requires minimum 9 iterations, 7 in the first cost function and 2 in the second cost function. For generalized PTC in [17] the number of iterations is 10 because in the first cost function 3 candidates are passed to the second cost function to avoid an unstable response. The parallel PTC [5] evaluates the two cost functions separately for all 7 vector candidates and then chooses between 2 to 4 vector candidates from each cost function minimization to find one that provides the best compromise for both cost functions.

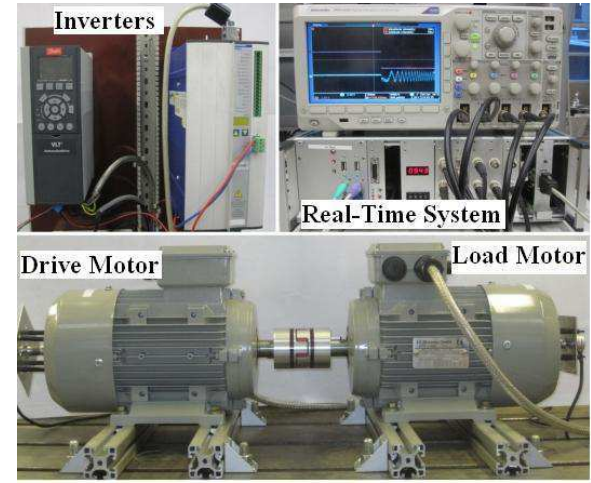

Fig. 14: Experimental setup used for validation of the designed cost function parameters.

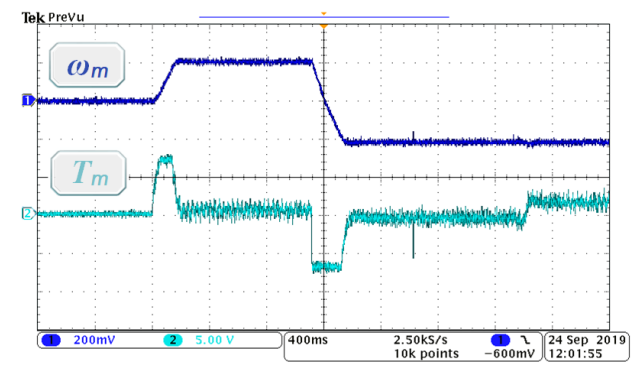

(a) Drive speed (200 rad/s/div) and torque ( $5 \mathrm{Nm} / \mathrm{div})$

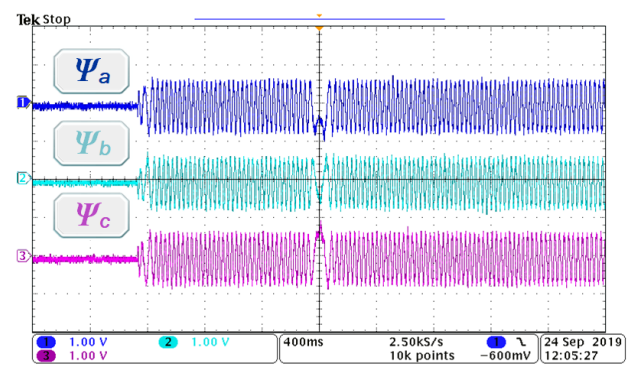

(b) Stator flux $(1 \mathrm{~Wb} /$ div $)$

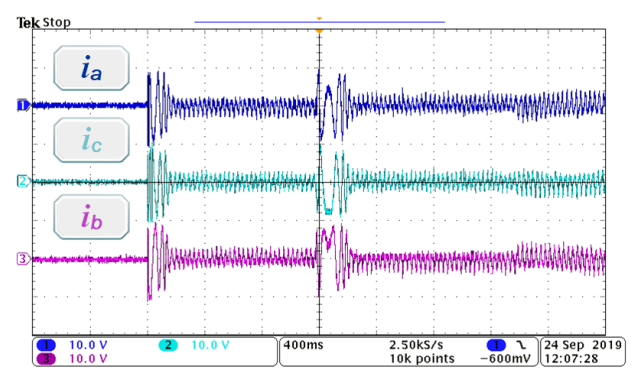

(c) Stator currents $(10 \mathrm{~A} / \mathrm{div})$

Fig. 15: Experimental waveforms for (12) and $T_{\text {load }}=2 \mathrm{Nm}$, $f_{1}=2.5 \mathrm{kHz}\left(\lambda_{\Psi}=9.64, \lambda_{s w}=0.13\right.$ and $\left.\Psi_{s}^{*}=0.65\right)$.

\section{CONCLUSION}

An ANN based weighting factor design method is applied to select the optimal parameters of the cost function in the PTC algorithm controlling a motor drive. Different load conditions and reference set-points presented new sets of optimal parameters that have analytical guarantee to keep the defined performance metrics in the fitness function. For the larger load torque values, it was observed that the set of 


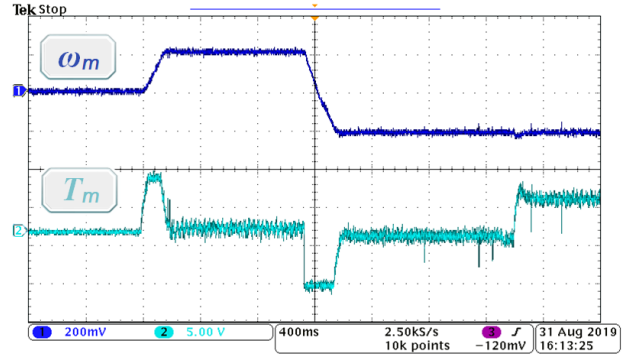

(a) Drive speed $(200 \mathrm{rad} / \mathrm{s} / \mathrm{div})$ and torque $(5 \mathrm{Nm} / \mathrm{div})$

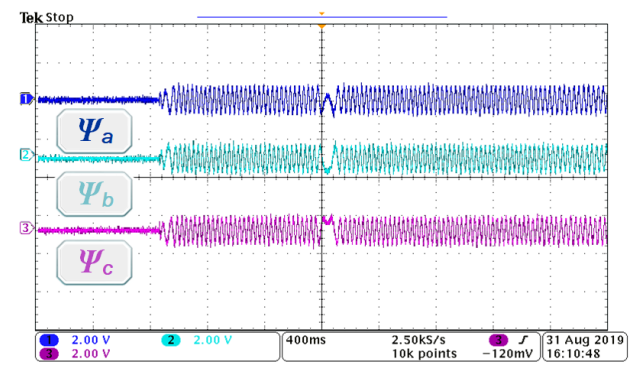

(b) Stator flux (2 Wb/div)

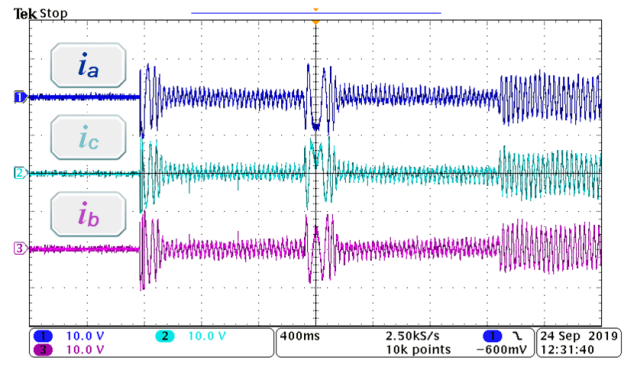

(c) Stator currents $(10 \mathrm{~A} / \mathrm{div})$

Fig. 16: Experimental waveforms for (12) and $T_{\text {load }}=5 \mathrm{Nm}$, $f_{1}=2.5 \mathrm{kHz}\left(\lambda_{\Psi}=10, \lambda_{s w}=0.1\right.$ and $\left.\Psi_{s}^{*}=0.67\right)$.

optimal cost function parameters is narrowing. Moreover, by including the flux reference as one of the design parameters, it was also observed that for one reference value not only one pair of weighting factors can provide the desired performance metrics. If the procedure is repeated for more load torque and reference speed values, the full operating region of the drive can be optimized. Experimental results have confirmed that the selected optimum cost function parameters can provide a good performance during the drive operation.

A comparison with the traditional branch and bound design method showed that the design process needs to be iteratively repeated, while for the ANN method the whole range of the cost function parameters is covered in one design step. In addition the selection of the optimal parameters is much simpler using the fitness function since the design for different performance factors can just be changed by defining a new fitness function. In the conventional method the whole procedure of performing the simulations with the branch and bound algorithm would need to be repeated many times.

\section{ACKNOWLEDGMENT}

J. Rodriguez acknowledges the support of ANID through projects FB0008, ACT192013 and 1170167.

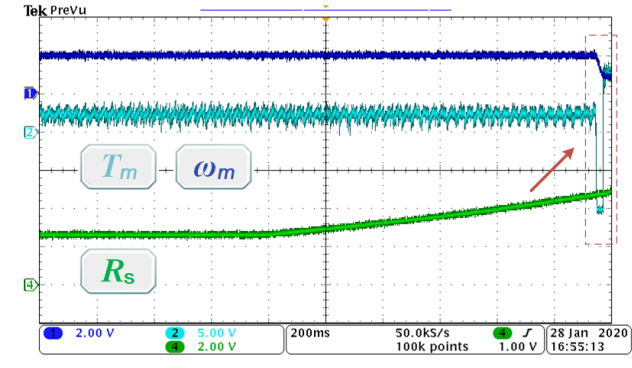

(a) Drive speed $(200 \mathrm{rad} / \mathrm{s} / \mathrm{div})$, torque $(5 \mathrm{Nm} / \mathrm{div})$ and stator resistance $(2 \Omega / \mathrm{div})$.

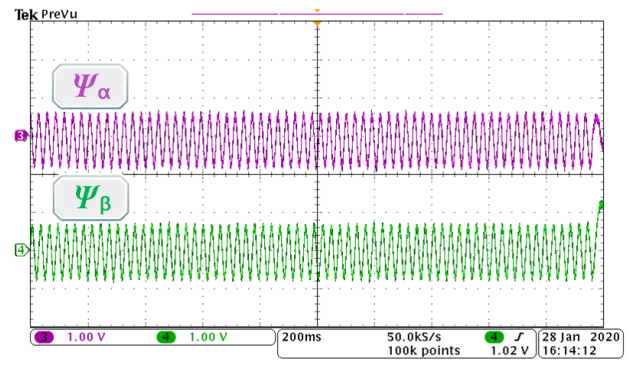

(b) Stator flux (1 Wb/div)

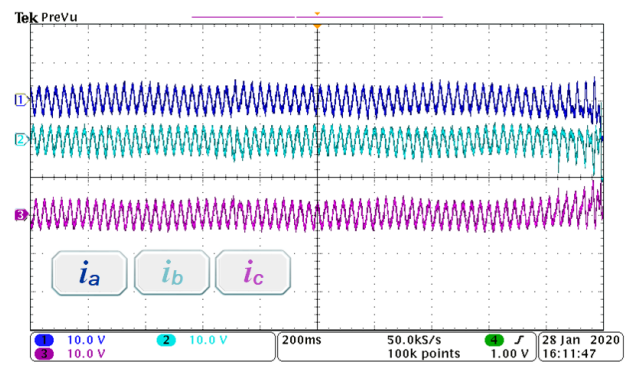

(c) Stator currents (2 A/div)

Fig. 17: Experimental waveforms for $R_{s}=2.65-4 \Omega$ and $T_{\text {load }}=2 \mathrm{Nm} .\left(\lambda_{\Psi}=9.64, \lambda_{s w}=0.13\right.$ and $\left.\Psi_{s}^{*}=0.65\right)$.

\section{REFERENCES}

[1] S. Vazquez, J. Rodriguez, M. Rivera, L. G. Franquelo, and M. Norambuena, "Model predictive control for power converters and drives: Advances and trends," IEEE Trans. Ind. Electron., vol. 64, no. 2, pp. 935-947, Feb. 2017.

[2] J. I. Leon, S. Kouro, L. G. Franquelo, J. Rodriguez, and B. Wu, "The essential role and the continuous evolution of modulation techniques for voltage-source inverters in the past, present, and future power electronics," IEEE Trans. Ind. Electron., vol. 63, no. 5, pp. 2688-2701, May. 2016.

[3] P. Karamanakos, T. Geyer, and S. Manias, "Direct voltage control of DCDC boost converters using enumeration-based model predictive control," IEEE Trans. Power Electron., vol. 29, no. 2, pp. 968-978, Feb. 2014.

[4] M. Norambuena et al., "A very simple strategy for high-quality performance of AC machines using model predictive control," IEEE Tran. Power Electron., vol. 34, no. 1, pp. 794-800, Jan. 2019.

[5] F. Wang et al., "Parallel predictive torque control for induction machines without weighting factors," IEEE Trans. Power Electron., vol. 35, no. 2, pp. 1779-1788, Feb. 2020.

[6] Y. Yang, H. Wen, M. Fan, M. Xie, and R. Chen, "Fast finite-switchingstate model predictive control method without weighting factors for ttype three-level three-phase inverters," IEEE Trans. Ind. Inform., vol. 15, no. 3, pp. 1298-1310, Mar. 2019.

[7] F. Donoso et al., "Finite-set model-predictive control strategies for a $3 \mathrm{~L}-$ NPC inverter operating with fixed switching frequency," IEEE Trans. Ind. Electron., vol. 65, no. 5, pp. 3954-3965, May. 2018.

[8] Z. Gong et. al, "Design and experimental evaluation of fast model 


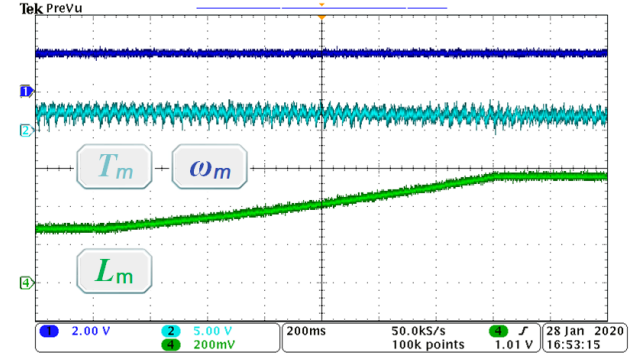

(a) Drive speed (200 rad/s/div), torque (5 Nm/div) and mutual inductance $(0.2 \mathrm{mH} / \mathrm{div})$

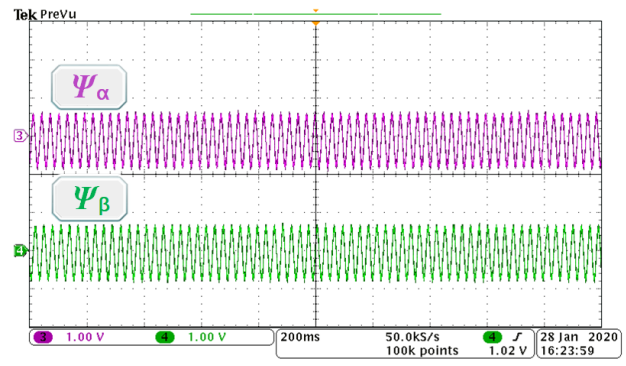

(b) Stator flux (1 Wb/div)

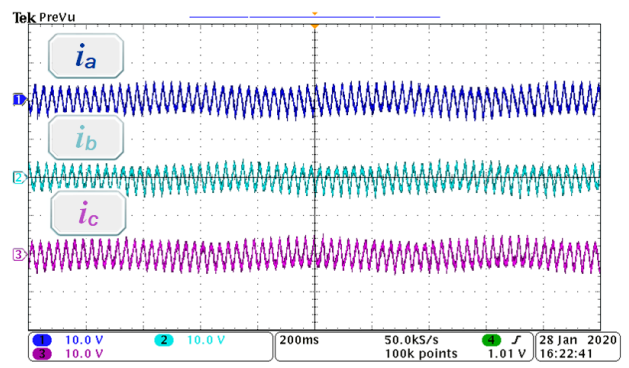

(c) Stator currents $(5 \mathrm{~A} / \mathrm{div})$

Fig. 18: Experimental waveforms for $L_{m}=2.75-5 \mathrm{mH}$ and $T_{\text {load }}=2 \mathrm{Nm}\left(\lambda_{\Psi}=9.64, \lambda_{s w}=0.13\right.$ and $\left.\Psi_{s}^{*}=0.65\right)$.

predictive control for modular multilevel converters," IEEE Trans. Ind. Electron., vol. 63, no. 6, pp. 3845-3856, Jun. 2016.

[9] P. Cortes et al., "Guidelines for weighting factors design in model predictive control of power converters and drives," in Proc. of ICIT 2009, pp. 1-7, Feb. 2009.

[10] E. Fuentes, C. A. Silva, and R. M. Kennel, "MPC implementation of a quasi-time-optimal speed control for a PMSM drive, with inner modulated-FS-MPC torque control," IEEE Trans. Ind. Electron., vol. 63, no. 6, pp. 3897-3905, Jun. 2016.

[11] Y. Zhang and H. Yang, "Two-vector-based model predictive torque control without weighting factors for induction motor drives," IEEE Trans. Power Electron., vol. 31, no. 2, pp. 1381-1390, Feb. 2016.

[12] W. Xu, J. Zou, Y. Liu, and J. Zhu, "Weighting factorless model predictive thrust control for linear induction machine," IEEE Trans. Power Electron., vol. 34, no. 10, pp. 9916-9928, Oct. 2019.

[13] W. Wu, D. Wang, and L. Liu, "A multi-layer sequential model predictive control of three-phase two-leg seven-level t-type nested neutral point clamped converter without weighting factors," IEEE Access, vol. 7, pp. 162 735-162 746, 2019.

[14] J. Zhang, L. Li, M. Norambuena, J. Rodriguez, and D. G. Dorrell, "Sequential model predictive control of direct matrix converter without weighting factors," in Proc. of IECON 2018, pp. 1477-1482, Oct. 2018.

[15] R. E. Kodumur Meesala, V. P. K. Kunisetti, and V. Kumar Thippiripati, "Enhanced predictive torque control for open end winding induction motor drive without weighting factor assignment," IEEE Trans. Power Electron., vol. 34, no. 1, pp. 503-513, Jan. 2019.

[16] P. G. Ipoum-Ngome, D. L. Mon-Nzongo, J. Song-Manguelle, R. C. C. Flesch, and T. Jin, "Optimal finite state predictive direct torque control without weighting factors for motor drive applications," IET Power Electron., vol. 12, no. 6, pp. 1434-1444, 2019.

[17] Y. Zhang, B. Zhang, H. Yang, M. Norambuena, and J. Rodriguez, "Generalized sequential model predictive control of im drives with fieldweakening ability," IEEE Trans. Power Electron., vol. 34, no. 9, pp. 8944-8955, 2019.

[18] F. Villarroel et al., "Multiobjective switching state selector for finitestates model predictive control based on fuzzy decision making in a matrix converter," IEEE Trans. Ind. Electron., vol. 60, no. 2, pp. 589599, Feb. 2013

[19] C. A. Rojas et al., "Predictive torque and flux control without weighting factors," IEEE Trans. Ind. Electron., vol. 60, no. 2, pp. 681-690, Feb. 2013.

[20] L. M. A. Caseiro, A. M. S. Mendes, and S. M. A. Cruz, "Dynamically weighted optimal switching vector model predictive control of power converters," IEEE Trans. Ind. Electron., vol. 66, no. 2, pp. 1235-1245, Feb. 2019

[21] Z. Zhang, W. Tian, W. Xiong, and R. Kennel, "Predictive torque control of induction machines fed by 3L-NPC converters with online weighting factor adjustment using fuzzy logic," in Proc. of ITEC 2017, pp. 84-89, Jun. 2017.

[22] O. Machado, P. Martin, F. J. Rodriguez, and E. J. Bueno, "A neural network-based dynamic cost function for the implementation of a predictive current controller," IEEE Trans. Ind. Informatics, vol. 13, no. 6, pp. 2946-2955, Dec. 2017.

[23] T. Dragicevic and M. Novak, "Weighting factor design in model predictive control of power electronic converters: An artificial neural network approach," IEEE Trans. Ind. Electron., vol. 66, no. 11, pp. 8870-8880, Nov. 2019.

[24] P. Zanchetta, "Heuristic multi-objective optimization for cost function weights selection in finite states model predictive control," in Proc. of PRECEDE 2011, pp. 70-75, Oct. 2011.

[25] P. R. U. Guazzelli, W. C. de Andrade Pereira, C. M. R. de Oliveira, A. G. de Castro, and M. L. de Aguiar, "Weighting factors optimization of predictive torque control of induction motor by multiobjective genetic algorithm," IEEE Trans. Power Electron., vol. 34, no. 7, pp. 6628-6638, Jul. 2019.

[26] M. B. Shadmand, S. Jain, and R. S. Balog, "Autotuning technique for the cost function weight factors in model predictive control for power electronic interfaces," IEEE J. Emer. and Sel. Topics Power Electron., vol. 7, no. 2, pp. 1408-1420, Jun. 2019.

[27] A. Bhowate, M. Aware, and S. Sharma, "Predictive torque control with online weighting factor computation technique to improve performance of induction motor drive in low speed region," IEEE Access, vol. 7, pp. 42 309-42 321, 2019.

[28] M. Novak, U. M. Nyman, T. Dragicevic, and F. Blaabjerg, "Analytical design and performance validation of finite set MPC regulated power converters," IEEE Trans. Ind. Electron., vol. 66, no. 3, pp. 2004-2014, Mar. 2019.

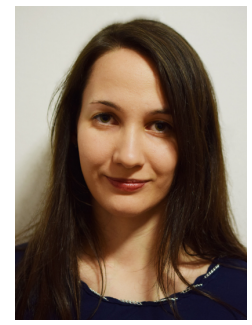

M. Novak (S'17-M'20) received the M.Sc. degree in Electrical Engineering and Information Technology from Zagreb University, Croatia, in 2014 and the Ph.D degree in Electrical Engineering from Aalborg University, Denmark, in 2020. She is currently working as a postdoctoral researcher at Department of Energy Technology, Aalborg University, Denmark.

Until 2016 she was working as a Research Associate at Faculty of Electrical Engineering and Computing, Zagreb University, Croatia. In 2018 she was a visiting researcher at the Chair of Power Electronics, Kiel University, Kiel, Germany.

Dr. Novak is the recipient of EPE Outstanding Young EPE Member Award for the year 2019. Her research interests include model predictive control, multilevel converters, statistical model checking, reliability of power electronic systems and renewable energy systems. 


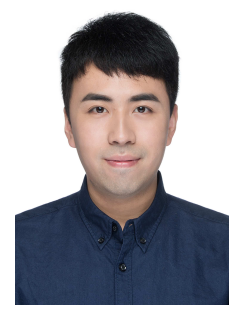

machine drive system.

H. Xie (S'19) was born in Jiangsu Province, China, in 1990. He received the B.S. and M.Sc degrees in Electronic Engineering from Nanjing University of Aeronautics and Astronautics, Nanjing, China, in 2013 and 2017, respectively.

Since 2017, he is currently working toward the Ph.D degree in the Chair of Electrical Drive Systems and Power Electronics, Technical University of Munich, Munich, Germany.

His research interests include modern predictive control, sensorless control for electrical

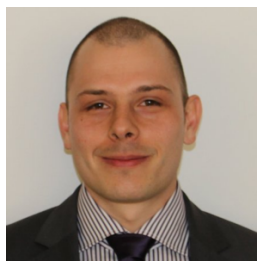

T. Dragicevic (S'09-M'13-SM'17) received the M.Sc. and the industrial Ph.D. degrees in Electrical Engineering from the Faculty of Electrical Engineering, University of Zagreb, Croatia, in 2009 and 2013, respectively. From 2013 until 2016 he has been a Postdoctoral researcher at Aalborg University, Denmark. From 2016 until 2020 he was an Associate Professor at Aalborg University, Denmark. From 2020 he is a Professor at the Technical University of Denmark.

He made a guest professor stay at Nottingham University, UK during spring/summer of 2018. His research interest is application of advanced control, optimization and artificial intelligence inspired techniques to provide innovative and effective solutions to emerging challenges in design, control and cyber-security of power electronics intensive electrical distributions systems and microgrids. $\mathrm{He}$ has authored and co-authored more than 230 technical publications (more than 100 of them are published in international journals, mostly in IEEE), 8 book chapters and a book in the field.

He serves as an Associate Editor in the IEEE TRANSACTIONS ON INDUSTRIAL ELECTRONICS, in IEEE TRANSACTIONS ON POWER ELECTRONICS, in IEEE Emerging and Selected Topics in Power Electronics and in IEEE Industrial Electronics Magazine. Dr. Dragicevic is a recipient of the Koncar prize for the best industrial $\mathrm{PhD}$ thesis in Croatia, a Robert Mayer Energy Conservation award, and he is a winner of an Alexander von Humboldt fellowship for experienced researchers.

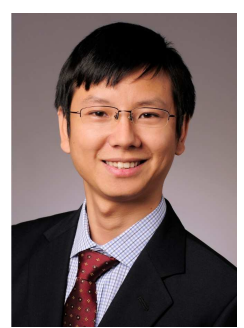

F. Wang (S'13-M'14-SM'18) was born in Jiujiang, China, in 1982. He received the B.S. degree in electronic engineering and the M.S. degree in automation from Nanchang Hangkong University, Nanchang, China, in 2005 and 2008, respectively. In 2014 he received Ph.D. degree at the Institute for Electrical Drive Systems and Power Electronics, Technische Universitaet Muenchen, Munich, Germany.

Currently he is working as full professor and deputy director of Quanzhou Institute of Equipment Manufacturing, Haixi Institutes, Chinese Academy of Sciences, China. He serves as IET Fellow, IEEE Senior Member, Associate Editor for IEEE Transactions on Industrial Electronics and IEEE Transactions on Energy Conversion. As General Chair, he organized IEEE 5th International Symposium on Predictive Control of Electrical Drives and Power Electronics (PRECEDE). His research interests include predictive control and sensorless control for electrical drives and power electronics.

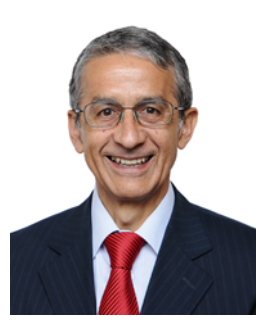

J. Rodriguez (M'81-SM'94-F'10) received the Engineer degree in electrical engineering from the Universidad Tecnica Federico Santa Maria in Valparaiso, Chile, in 1977 and the Dr.-Ing. degree in electrical engineering from the University of Erlangen, Erlangen, Germany, in 1985. He has been with the Department of Electronics Engineering, Universidad Tecnica Federico Santa Maria, since 1977, where he was full Professor and President. Since 2015 he was the President and since 2019 he is full professor at Universidad Andres Bello in Santiago, Chile.

He has coauthored two books, several book chapters and more than 400 journal and conference papers. His main research interests include multilevel inverters, new converter topologies, control of power converters, and adjustable-speed drives. He has received a number of best paper awards from journals of the IEEE.

Dr. Rodriguez is member of the Chilean Academy of Engineering. In 2014 he received the National Award of Applied Sciences and Technology from the government of Chile. In 2015 he received the Eugene Mittelmann Award from the Industrial Electronics Society of the IEEE. In years 2014 to 2019 he has been included in the list of Highly Cited Researchers published by Web of Science.

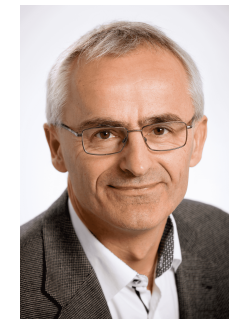

F. Blaabjerg (S'86-M'88-SM'97-F'03) was with ABB-Scandia, Randers, Denmark, from 1987 to 1988. From 1988 to 1992, he got the PhD degree in Electrical Engineering at Aalborg University in 1995. He became an Assistant Professor in 1992, an Associate Professor in 1996, and a Full Professor of power electronics and drives in 1998. From 2017 he became a Villum Investigator. $\mathrm{He}$ is honoris causa at University Politehnica Timisoara (UPT), Romania and Tallinn Technical University (TTU) in Estonia.

His current research interests include power electronics and its applications such as in wind turbines, PV systems, reliability, harmonics and adjustable speed drives. He has published more than 600 journal papers in the fields of power electronics and its applications. He is the co-author of four monographs and editor of ten books in power electronics and its applications.

He has received 32 IEEE Prize Paper Awards, the IEEE PELS Distinguished Service Award in 2009, the EPE-PEMC Council Award in 2010, the IEEE William E. Newell Power Electronics Award 2014, the Villum Kann Rasmussen Research Award 2014, the Global Energy Prize in 2019 and the 2020 IEEE Edison Medal. He was the Editorin-Chief of the IEEE TRANSACTIONS ON POWER ELECTRONICS from 2006 to 2012. He has been Distinguished Lecturer for the IEEE Power Electronics Society from 2005 to 2007 and for the IEEE Industry Applications Society from 2010 to 2011 as well as 2017 to 2018. In 20192020 he serves a President of IEEE Power Electronics Society. He is Vice-President of the Danish Academy of Technical Sciences too. He is nominated in 2014-2019 by Thomson Reuters to be between the most 250 cited researchers in Engineering in the world. 